\title{
A rare case of advanced lung cancer presenting as a symptomatic gastric tumor
}

\author{
CORNELIA NITIPIR $^{1}$, OCTAV GINGHINA ${ }^{2}$, LILIANA POPA ${ }^{3}$, FLORIN ANDREI $^{4}$, NICOLAIE TUDOR ${ }^{5}$, \\ IRINA RADU ${ }^{1}$, CRISTIAN IACIU ${ }^{1}$, CRISTINA ORLOV ${ }^{1}$, FLORINA VASILESCU ${ }^{6}$, CRISTIAN BALALAU ${ }^{7}$, \\ GRIGORIS LEON $^{8}$, CAROLINA NEGREI $^{9}$ and MARIA ALEXANDRA BARBU ${ }^{1}$ \\ ${ }^{1}$ Department of Oncology, Elias University Clinical Hospital, Carol Davila University, Medicine and Pharmacy Faculty, \\ 011461 Bucharest; ${ }^{2}$ Department of Surgery, 'Sf. Ioan' Clinical Emergency Hospital, Carol Davila University, Faculty \\ of Dental Medicine, 042122 Bucharest; Departments of ${ }^{3}$ Dermatology, ${ }^{4}$ Histopathology and ${ }^{5}$ Gastroenterology, Elias \\ University Clinical Hospital, Carol Davila University, Medicine and Pharmacy Faculty, 011461 Bucharest; ${ }^{6}$ Department \\ of Pathology, Emergency University Military Hospital, Carol Davila University, Medicine and Pharmacy Faculty, \\ 020021 Bucharest; ${ }^{7}$ Department of Surgery, 'Sf. Pantelimon' Clinical Emergency Hospital, Carol Davila University, \\ Medicine and Pharmacy Faculty, 021659 Bucharest, Romania; ${ }^{8}$ Department of Forensic Medicine and Toxicology, \\ National and Kapodistrian University of Athens, Medical School, 10679 Athens, Greece; ${ }^{9}$ Department of Toxicology, \\ Faculty of Pharmacy, 'Carol Davila' University of Medicine and Pharmacy, 020956 Bucharest, Romania
}

Received December 12, 2017; Accepted January 12, 2018

DOI: $10.3892 / \mathrm{mco} .2018 .1565$

\begin{abstract}
Although gastric metastases have been estimated to occur in less than $2 \%$ of cancer patients, an increased use of upper digestive tract endoscopy allows for a higher detection of secondary gastric tumors. We describe the case of a 66-year-old male patient presenting with mild pain in the sternum and upper abdominal area. Physical examination revealed a right parietal skull tumor, with no other significant clinical changes. Upon exclusion of an acute coronary syndrome, upper digestive tract endoscopy was performed, showing the presence of an ulcerated tumor located in the gastric fundus. Histopathologic examination of the biopsy sample and immunohistochemical tests suggested a pulmonary origin of the gastric tumor. Whole body computer tomography showed the presence of tumors in the gastric fundus, left lung, liver, kidneys, bones and brain. Transbronchial biopsy of the lung tumor certified the diagnosis of non-small cell lung cancer, with the same immunohistochemical profile as the gastric tumor. Hence, it was considered the origin of the metastases. Biopsy of the skull tumor also had the identical tumor histology. Whole brain radiotherapy was performed for the brain metastases and subsequent chemotherapy was
\end{abstract}

Correspondence to: Dr Octav Ginghina, Department of Surgery, 'Sf. Ioan' Clinical Emergency Hospital, Carol Davila University, Faculty of Dental Medicine, 13 Vitan Barzesti Street, 042122 Bucharest, Romania

E-mail: sciencecontactemail@gmail.com

Key words: immunohistochemistry, gastric metastases, non-small cell lung cancer administered. Although non-specific, gastrointestinal signs and symptoms occurring in lung cancer patients should alert the clinicians as to the possibility of gastrointestinal metastases and prompt endoscopic evaluation.

\section{Introduction}

During the last 20 years, novel therapies for lung cancer have led to the prevention of more than 1.7 million deaths (1). Even with this optimistic news, lung cancer remains the leading cause of death in USA (1). Approximately $50 \%$ of lung cancer patients have widespread metastatic disease at presentation, most frequently with cerebral, hepatic or adrenal involvement. The gastrointestinal tract is only rarely involved (2). The prognosis of gastric metastases with origin in lung cancer is very poor, survival rates being estimated at $20 \%$ at 1 year and $1 \%$ at 5 years $(3,4)$. Although gastric metastases of lung cancer were believed to be exceptionally rare, autopsy studies report an incidence ranging from 0.19 to $\geq 11 \%$ (5-9).

Gastric metastases are rarely symptomatic and therefore easily overlooked when investigating lung cancer patients (10). Nevertheless, gastrointestinal bleeding and perforation have been reported and are often fatal. In light of these findings, an increased use of esophagogastroduodenoscopy may be needed to achieve a higher detection of secondary gastric tumors. For the early detection of gastric tumors one can enhance the performances of esophagogastroduodenoscopy by associating narrow band imaging (NBI) technology and in vivo staining examination techniques $(11,12)$. The most frequent staining agents used for the assessment of digestive tract tumors are methylene blue, toluidine blue and Lugol iodine (13-15). The NBI technology improves specificity, sensitivity and accuracy of the methylene blue video staining method providing essential information regarding the superficial vascular network and 
the features of the cellular field (11). A thorough evaluation of tumor cell-specific characteristics utilizing ELISA assay and flow cytometry can improve the diagnostic and treatment protocol (16).

In the present study, we report a case of advanced lung cancer presenting as a symptomatic gastric tumor. This is an infrequent situation, only a few similar cases being reported in the past decades, to the best of our knowledge. We discuss the clinicopathological features of secondary gastric cancer with emphasis on the differential diagnosis and review the available treatment options.

\section{Case report}

A 66-year-old male patient, with a history of smoking, was admitted in August 2015 in the Department of Cardiology Elias Emergency Hospital (Bucharest, Romania) for mild pain in the sternum and upper abdominal area for $>4 \mathrm{~h}$. The physical examination revealed the presence of a right parietal skull tumor, the rest of the general examination being unremarkable. All cardiac causes for the pain were excluded and the patient was referred to the Department of Gastroenterology. Abdominal ultrasound was not relevant due to the patient's lack of compliance. Upper gastrointestinal endoscopy showed the presence of an ulcerated tumor $80 \times 70 \mathrm{~mm}$ in size located in the gastric fundus.

Multiple endoscopic biopsies were performed as well as a histopathologic examination, followed by hematoxylin and eosin and immunohistochemical staining. Positive tumor protein 63 (P63), positive cytokeratin 34ßE12 (CK34ßE12), weakly positive thyroid transcriptional factor-1 (TTF-1), negative cytokeratin 7 (CK7) and negative carcinoembryonic antigen (CEA) (Fig. 1) confirmed the diagnosis of gastric metastasis of pulmonary origin.

Whole body computed tomography (CT) scan identified multiple tumors: One in the gastric fundus, one in the left lung and numerous tumors in the liver, kidneys, bones and brain, the clinical stage being cT2N3M1. Bronchoscopy and transbronchial biopsy of the left lung tumor were carried out to establish the origin of the lung tumor (Fig. 2) leading to the diagnosis of squamous cell carcinoma (SCC) or non-small cell lung cancer. As the lung and gastric tumor had identical immunohistochemical profiles, it was considered the origin of the metastases. The tissue tested negatively for EGFR mutation and no ALK rearrangement was reported. Biopsy of the skull tumor also showed the same histologic pattern (Fig. 3).

Laboratory findings showed no specific changes. Whole brain radiotherapy was performed for the brain metastases (total dose, 30 Gy). It was well tolerated, with no serious adverse events. Following radiotherapy, the patient underwent chemotherapy with paclitaxel $200 \mathrm{mg} / \mathrm{m}^{2}$ and carboplatin AUC6 and osteoclast inhibitors (zoledronic acid), measured as q3w. After the second cycle, grade II aplastic anemia and mild elevation of liver enzymes occurred. Nevertheless, the oncology board, comprising a medical oncologist, gastroenterologists and hematologists continued the aggressive treatment, with daily monitoring of the hemogram and liver enzymes.

The patient received 6 cycles of chemotherapy, with stable disease, according to response evaluation criteria in solid tumors (RECIST). Due to grade IV anemia and hepatotoxicity from chemotherapy, oncological treatment was ceased and the patient offered best supportive care. The patient succumbed four weeks later to multiple organ failure.

\section{Discussion}

Gastric site metastasis from primary lung cancer was rarely reported, portending an inferior prognosis even with aggressive oncologic treatment (17). Breast cancer, esophageal cancer, melanoma, as well as testicular seminoma, hepatocellular carcinoma, choriocarcinoma and Merkel cell carcinoma can also be the origin of secondary gastric tumors and should be included in the differential diagnosis (18-21).

In 1993, large cell lung cancer was reported to be the most common histologic type of primary lung cancer associated with gastric metastases (22). Nevertheless, according to more recent reports, pulmonary adenocarcinoma has become the leading disease, followed by SCC, small cell lung cancer, and pleomorphic carcinoma of the lung (23). The distinction between subtypes is critical for the selection of appropriate targeted therapies (erlotinib/crizotinib/bevacizumab/pemetrexed).

Lung cancer cells spread hematogenously to the gastric submucosa (17). The tumor is thus clinically silent until it reaches considerable sizes. Although non-specific, symptoms and signs such as epigastric pain, vomiting, anorexia and chronic upper gastrointestinal bleeding manifesting as melena and anemia occurring in cancer patients should alert the clinician and prompt endoscopic evaluation $(17,24)$. However, such complaints are generally misinterpreted as side-effects of chemotherapy. Severe complications including acute bleeding and perforation may also occur and are usually lethal.

Endoscopic findings can mimic other gastric tumors, but a volcano-like or umbilicated mass ('the bull's eye sign') is considered a classic endoscopic appearance of metastatic gastric cancer, as was first suggested by Pomerantz and Margolin in 1962 (25). Nodules, solitary or multiple, sometimes ulcerated polypoid submucosal masses, as well as infiltrating constricting tumors have also been described (25-28). The most frequent locations of gastric metastases are reported to be the middle or upper third of the stomach. Usually, the greater curvature is involved $(29,30)$. Given the variable morphology and the lack of characteristic appearances on endoscopy, metastases to the stomach may also be confused with gastric ulcer, ectopic pancreas, eosinophilic granuloma, lymphoma, carcinoid and Kaposi's sarcoma (31).

The histopathologic examination of gastric tumors in lung cancer patients raises yet another diagnostic challenge given the difficulty to distinguish between a metastasis from primary lung cancer and an initial gastric cancer, especially when considering adenocarcinoma. Hence, immunohistochemical tests are the most important step in the diagnostic algorithm of these cases and are crucial for optimal management (26). The common markers used for subtyping non-small cell lung cancer include TTF-1, CK7, Napsin-A for adenocarcinoma and p63, CK5/6, and CK34ßE12/CK903 for SCC (32). In our patient, the positive P63 and CK34 $3 \mathrm{E} 12$ staining and the weakly positive TTF-1 staining support the lung origin of the metastasis. 

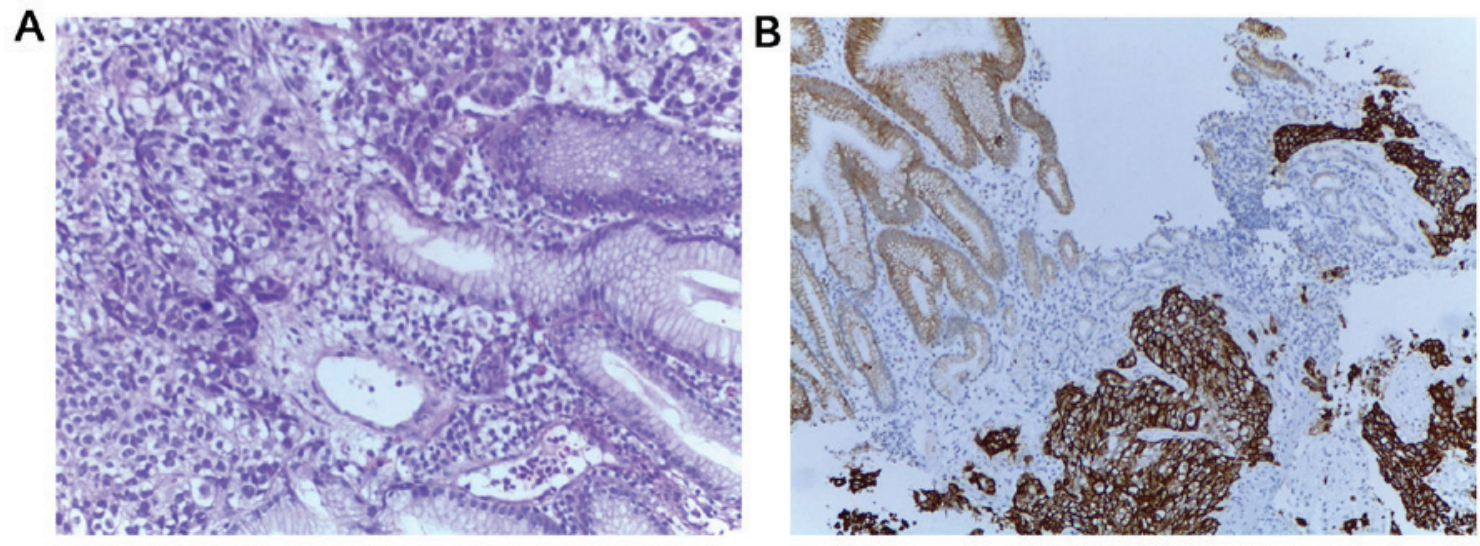

Figure 1. (A) Hematoxylin and eosin (x20) and immunohistochemical staining (x10) results of the gastric tumor biopsy showing poorly differentiated carcinoma. (B) Strongly positive CK34ßE12 staining.
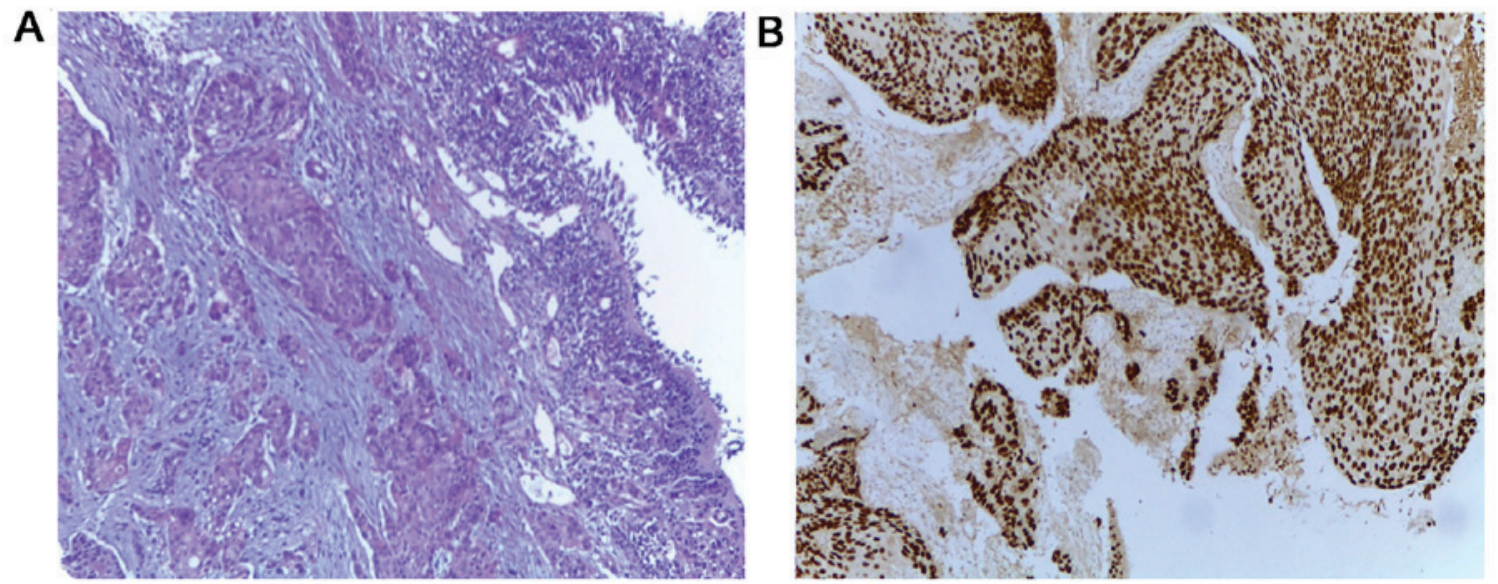

Figure 2. (A) Hematoxylin and eosin (x10), and (B) immunohistochemical staining (x10) results of the transbronchial lung biopsy showing the invasion of squamous cell carcinoma and expression of $\mathrm{P} 63$.
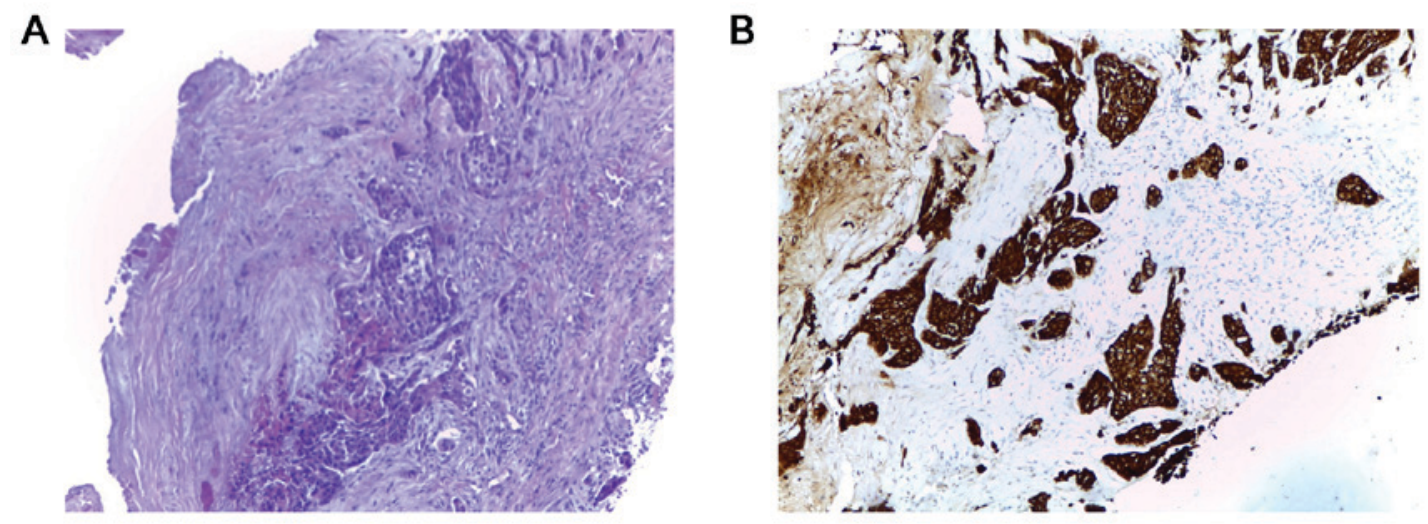

Figure 3. Hematoxylin and eosin (x10) and immunohistochemical staining (x10) results of the skull tumor biopsy showing carcinoma with morphology similar to that of the primary tumor in (A) the lung. (B) Strongly positive CK34ßE12 staining.

Serum tumor markers were tested in order to complete the diagnosis: CEA and SCC levels were 3-fold higher than normal values, CA 19-9 was within reasonable limits. It is known that, each serum tumor marker has its specificity and sensitivity and can be used mainly to establish the prognosis of the disease. Non-small cell lung cancer also demonstrated the overexpression of endocan (33). This marker of angiogenesis was studied in several types of cancer and was used as a possible prognostic factor in non-small cell lung cancer and gastrointestinal cancer (34-36).

Gastrointestinal metastases secondary to lung cancer represent a late stage of disease, usually being associated with 
metastases in other organs. Patients rarely survive longer than 16 weeks after diagnosis of gastrointestinal metastases (9).

The therapeutic management of such patients includes surgery, chemotherapy with or without radiotherapy, molecularly targeted therapies and supportive care. Surgical intervention in patients with lung cancer metastatic to the stomach remains controversial as some authors report longer survival rates in the best supportive care approach (37), while others support metastasectomy in patients with non-small cell lung cancer and unique metastasis not involving the brain or the adrenal gland $(38,39)$. However, life-threatening complications such as massive hemorrhage or perforation can be prevented by surgical intervention $(37,40)$. Therefore, treatment should be personalized. Our patient did not undergo surgery given the presence of multiple other extrathoracic metastases. We managed to control the disease and patient's symptoms for 22 weeks by offering 6 cycles of chemotherapy, radiation therapy and best supportive care when his performance status did not allow us to continue active oncological treatment.

In conclusion, although non-specific, gastrointestinal signs and symptoms occurring in lung cancer patients should alert the clinicians as to the possibility of gastrointestinal metastases and prompt endoscopic evaluation. Distinguishing between primary and secondary gastric tumors can be challenging and requires immunohistochemical tests. Early detection of gastric metastases and initiation of appropriate treatment can improve the patient's quality of life and prolong patient survival.

\section{References}

1. Siegel RL, Miller KD and Jemal A: Cancer statistics, 2016. CA Cancer J Clin 66: 7-30, 2016.

2. van Meerbeeck JP, Fennell DA and De Ruysscher DK: Small-cell lung cancer. Lancet 378: 1741-1755, 2011.

3. Yang CJ, Hwang JJ, Kang WY, Chong IW, Wang TH, Sheu CC, Tsai JR and Huang MS: Gastro-intestinal metastasis of primary lung carcinoma: Clinical presentations and outcome. Lung Cancer 54: 319-323, 2006.

4. Greenlee RT, Hill-Harmon MB, Murray T and Thun M: Cancer statistics, 2001. CA Cancer J Clin 51: 15-36, 2001.

5. Green LK: Hematogenous metastases to the stomach. A review of 67 cases. Cancer 65: 1596-1600, 1990.

6. Kim MS, Kook EH, Ahn SH, Jeon SY, Yoon JH, Han MS, Kim CH and Lee JC: Gastrointestinal metastasis of lung cancer with special emphasis on a long-term survivor after operation. J Cancer Res Clin Oncol 135: 297-301, 2009.

7. Kim SY, Ha HK, Park SW, Kang J, Kim KW, Lee SS, Park SH and Kim AY: Gastrointestinal metastasis from primary lung cancer: CT findings and clinicopathologic features. AJR Am J Roentgenol 193: W197-W201, 2009.

8. Hillers TK, Sauve MD and Guyatt GH: Analysis of published studies on the detection of extrathoracic metastases in patients presumed to have operable non-small cell lung cancer. Thorax 49: 14-19, 1994.

9. McNeill PM, Wagman LD and Neifeld JP: Small bowel metastases from primary carcinoma of the lung. Cancer 59: 1486-1489, 1987.

10. Antler AS, Ough Y, Pitchumoni CS, Davidian M and Thelmo W: Gastrointestinal metastases from malignant tumors of the lung. Cancer 49: 170-172, 1982.

11. Stefanescu DC, Ceachir O, Zainea V, Hainarosie M, Pietrosanu C, Ionita IG and Hainarosie R: Methilene blue video contact endoscopy enhancing methods. Rev Chim 67: 1558-1559, 2016.

12. Hainarosie R, Ceachir O, Zainea V, Hainarosie M, Pietrosanu C, Zamfir C and Stefanescu DC: The test of lugol iodine solution associated with NBI examination in early diagnostic of tongue carcinoma. Rev Chim 68: 226-227, 2017.
13. Stefanescu DC, Ceachir O, Zainea V, Hainarosie M, Pietrosanu C, Ionita IG and Hainarosie R: The use of methylene blue in assessing disease free margins during $\mathrm{CO}_{2}$ LASER assisted direct laryngoscopy for glottis cancer. Rev Chim 67: 1327-1328, 2016.

14. Hainarosie R, Zainea V, Ceachir O, Hainarosie M, Pietrosanu C and Stefanescu DC: The use of methylene blue in early detection of the vocal fold cancer. Rev Chim 68: 16-17, 2017.

15. Stefanescu DC, Ceachir O, Zainea V, Hainarosie M, Pietrosanu C, Ionita IG and Hainarosie R: The value of toluidine blue staining test in assessing disease free margins of oral cavity carcinomas. Rev Chim 67: 1255-1256, 2016.

16. Petrică-Matei GG, Iordache F, Hainăroşie R and Bostan M: Characterization of the tumor cells from human head and neck cancer. Rom J Morphol Embryol 57: 791-799, 2016.

17. Menuck LS and Amberg JR: Metastatic disease involving the stomach. Am J Dig Dis 20: 903-913, 1975.

18. Okazaki R, Ohtani H, Takeda K, Sumikawa T, Yamasaki A, Matsumoto S and Shimizu E: Gastric metastasis by primary lung adenocarcinoma. World J Gastrointest Oncol 2: 395-398, 2010.

19. McLemore EC, Pockaj BA, Reynolds C, Gray RJ, Hernandez JL, Grant CS and Donohue JH: Breast cancer: Presentation and intervention in women with gastrointestinal metastasis and carcinomatosis. Ann Surg Oncol 12: 886-894, 2005.

20. Lin CP, Cheng JS, Lai KH, Lo GH, Hsu PI, Chan HH, Hsu JH, Wang YY, Pan HB and Tseng HH: Gastrointestinal metastasis in hepatocellular carcinoma: Radiological and endoscopic studies of 11 cases. J Gastroenterol Hepatol 15: 536-541, 2000.

21. Senadhi V and Dutta S: Testicular seminoma metastasis to the gastrointestinal tract and the necessity of surgery. J Gastrointest Cancer 43: 499-501, 2012.

22. Hasegawa N, Yamasawa F, Kanazawa M, Kawashiro T, Kikuchi K, Kobayashi K, Ishihara T, Kuramochi S and Mukai M: Gastric metastasis of primary lung cancer. Nihon Kyobu Shikkan Gakkai Zasshi 31: 1390-1396, 1993 (In Chinese).

23. Huang Q, Su X, Bella AE, Luo K, Jin J, Zhang S, Luo G, Rong $\mathrm{T}$ and $\mathrm{Fu}$ J: Clinicopathological features and outcome of gastric metastases from primary lung cancer: A case report and systematic review. Oncol Lett 9: 1373-1379, 2015.

24. Casella G, Di Bella C, Cambareri AR, Buda CA, Corti G, Magri F, Crippa $\mathrm{S}$ and Baldini V: Gastric metastasis by lung small cell carcinoma. World J Gastroenterol 12: 4096-4097, 2006.

25. Pomerantz H and Margolin HN: Metastases to the gastrointestinal tract from malignant melanoma. Am J Roentgenol Radium Ther Nucl Med 88: 712-717, 1962.

26. Sileri P, D'Ugo S, Del Vecchio Blanco G, Lolli E, Franceschilli L, Formica V, Anemona L, De Luca C and Gaspari AL: Solitary metachronous gastric metastasis from pulmonary adenocarcinoma: Report of a case. Int J Surg Case Rep 3: 385-388, 2012.

27. Scobie BA: Malignant gastric ulcer due to metastasis. Australas Radiol 10: 119-123, 1966.

28. Hsu CC, Chen JJ and Changchien CS: Endoscopic features of metastatic tumors in the upper gastrointestinal tract. Endoscopy 28: 249-253, 1996.

29. Wu MH, Lin MT and Lee PH: Clinicopathological study of gastric metastases. World J Surg 31: 132-136, 2007.

30. Oda KH, Kondo H, Yamao T, Saito D, Ono H, Gotoda T, Yamaguchi H, Yoshida S and Shimoda T: Metastatic tumors to the stomach: Analysis of 54 patients diagnosed at endoscopy and 347 autopsy cases. Endoscopy 33: 507-510, 2001.

31. Kim YI, Kang BC and Sung SH: Surgically resected gastric metastasis of pulmonary squamous cell carcinoma. World J Gastrointest Surg 5: 278-281, 2013.

32. Reis-Filho JS, Carrilho C, Valenti C, Leitão D, Ribeiro CA, Ribeiro SG and Schmitt FC: Is TTF1 a good immunohistochemical marker to distinguish primary from metastatic lung adenocarcinomas? Pathol Res Pract 196: 835-840, 2000.

33. Grigoriu BD, Depontieu F, Scherpereel A, Gourcerol D, Devos P, Ouatas T, Lafitte JJ, Copin MC, Tonnel AB and Lassalle P: Endocan expression and relationship with survival in human non-small cell lung cancer. Clin Cancer Res 12: 4575-4582, 2006.

34. Waldner MJ, Wirtz S, Jefremow A, Warntjen M, Neufert C, Atreya R, Becker C, Weigmann B, Vieth M, Rose-John S, et al: VEGF receptor signaling links inflammation and tumorigenesis in colitis-associated cancer. J Exp Med 207: 2855-2868, 2010.

35. Hatfield KJ, Lassalle P, Leiva RA, Lindås R, Wendelboe $\varnothing$ and Bruserud $\varnothing$ : Serum levels of endothelium-derived endocan are increased in patients with untreated acute myeloid leukemia. Hematology 16: 351-356, 2011. 
36. Voiosu T, Bălănescu P, Bengus A, Voiosu A, Baicus CR Barbu M, Ladaru A, Nitipir C, Mateescu B, Diculescu M and Voiosu R: Serum endocan levels are increased in patients with inflammatory bowel disease. Clin Lab 60: 505-510 2014.

37. Lee PC, Lo C, Lin MT, Liang JT and Lin BR: Role of surgical intervention in managing gastrointestinal metastases from lung cancer. World J Gastroenterol 17: 4314-4320, 2011.

38. Aokage K, Yoshida J, Ishii G, Takahashi S, Sugito M, Nishimura M, Ochiai A and Nagai K: Long-term survival in two cases of resected gastric metastasis of pulmonary pleomorphic carcinoma. J Thorac Oncol 3: 796-799, 2008.
39. Salah S, Tanvetyanon $\mathrm{T}$ and Abbasi S: Metastatectomy for extra-cranial extra-adrenal non-small cell lung cancer solitary metastases: Systematic review and analysis of reported cases. Lung Cancer 75: 9-14, 2012.

40. Goh BK, Yeo AW, Koong HN, Ooi LL and Wong WK: Laparotomy for acute complications of gastrointestinal metastases from lung cancer: Is it a worthwhile or futile effort? Surg Today 37: 370-374, 2007 